\title{
Attitudes about Alzheimer's disease and the dementia service delivery network among family caregivers and service providers in rural Michigan
}

\author{
Cathleen M Connell, PhD \\ Sara L. Kole, MPH \\ Holly Avey, MPH \\ Christopher J. Benedict, MPH, MSW \\ Sid Gilman, MD
}

\begin{abstract}
The Community Outreach Education Program (COEP) was designed to provide educational interventions to disseminate information about the diagnosis, assessment, management, and treatment of dementia to health care professionals, service providers, staff of volunteer and community organizations and family caregivers. The present study describes one component of the needs assessment phase of the COEP-focus group interviews conducted with family caregivers and service providers. The predominant themes identified included myths and misconceptions about dementia, barriers to effective service delivery, and community strengths. The results were used to inform the curriculum and format of the community-based dementia education interventions designed for four sites in rural Michigan.
\end{abstract}

Cathleen M Connell, PhD, Associate Professor, Department of Health Behavior and Health Education. School of Public Health, Director. Education and Information Transfer Core, Michigan Alzheimer's Disease Research Center, University of Michigan, Ann Arbor, Michigan.

Sara L. Kole, MPH, Community Liaison, Michigan Public Health Institute, Okemos, Michigan.

Holly Avey, MPH, Health Educator, Michigan Alzheimer's Disease Research Center, University of Michigan, Ann Arbor, Michigan.

Christopher J. Benedict, MPH, MSW, Health Educator, Michigan Alzheimer's Disease Research Center, University of Michigan, Ann Arbor, Michigan.

Sid Gilman, MD, Director, Michigan Alzheimer's Disease Research Center, University of Michigan, Ann Arbor, Michigan.

\section{Introduction}

Although people with dementia and their care providers often need a wide range of services (e.g., diagnosis and assessment, respite care, in-home services), family members report that these services are difficult to obtain. Numerous barriers have been reported, including the lack of availability of needed services, poor coordination within the service delivery network, and limited communication among local agencies. ${ }^{1,2}$ Misconceptions and inaccurate information about dementia may also prevent or delay utilization of the health care system. For example, if it is commonly accepted that symptoms of dementia are part of the normal aging process and that there is nothing that can be done for a person with this disorder, family members will be unlikely to seek needed services. Denial of symptoms and reluctance to seek help can also be generated by feelings of shame, the stigma of dementia, suspicion of the health care system, and fear of institutionalization. ${ }^{4,5}$ In light of these widespread myths and misconceptions, it is not surprising that family members delay seeking a diagnosis and support services until a significant event or crisis triggers a response. Ideally, people with symptoms of dementia should receive prompt medical attention.

In rural areas, access to needed services and health professionals who are trained in dementia may be 
especially limited. ${ }^{6,7}$ For example, information and referral and diagnostic and assessment services are frequently less available in rural than in urban areas. Even when these services are available, families frequently report that transportation and traveling long distances to receive health care is a major concern. ${ }^{8.9}$ Finally, the value and belief systems of older rural residents, particularly the importance of self reliance and individualism, may decrease their willingness to seek and receive assistance. ${ }^{10,11}$

To address structural attitudinal barriers to seeking dementia services, community-based outreach efforts are needed to dispel myths and misconceptions, increase the coordination and cooperation among service providers, and disseminate accurate information about dementia and available services. ${ }^{12}$ Including representation from health care professionals, service providers, and staff of community organizations and voluntary agencies increases opportunities for identifying community goals, problems, and issues. Cooperative efforts help to develop community competence and empowerment, and provide a greater understanding of cultural values and beliefs. Familiarity with relevant channels of communication within the community facilitates the correct response to local needs and interests and ensures the institutionalization and longterm success of outreach efforts. ${ }^{13-15}$

The Community Outreach Education Program (COEP) was developed to disseminate information and skills related to the diagnosis, assessment, management and treatment of people with dementia to health care professionals, service providers, staff of relevant community organizations and voluntary agencies, and family members in Michigan. The long term objectives of the COEP are to increase awareness, utilization and coordination of the service delivery network, and foster an effective and knowledgeable community network that works collaboratively to improve care for patients with dementia and their families. Based on a community development model, all phases of the project are part of an outreach education process that facilitates community empowerment and mobilization to create change. ${ }^{16}$

The present study was conducted to explore:

- Knowledge of and attitudes about dementia and services for people with dementia;

- Perceived barriers to coordinated and effective service delivery; and

- Community strengths and resources.

Data were collected using focus group interviews coordinated by members of lay advisory boards established in four rural communities selected as COEP intervention sites. The interviews represent one component of a needs assessment conducted prior to the implementation of the COEP. Results will be shared with the community advisory boards, which will assist in the process of identifying needs and developing locally relevant educational interventions to improve the response to people with dementia and their families.

\section{Methods}

\section{Focus group interviews}

As described by Basch ${ }^{17}$ focus group interviews represent an important exploratory step conducted prior to the development and implementation of a comprehensive health education intervention. A focus group interview is "a qualitative approach used to obtain data about feelings and opinions of small groups of participants about a given problem, service, or other phenomenon." Focus groups have been used successfully to guide the development of a variety of health education interventions ${ }^{18}$ and are especially useful when exploring issues that people do not frequently discuss through normal channels of communication. ${ }^{19}$

The moderator of a focus group interview creates a non-threatening and supportive climate that encourages all group members to share their attitudes and opinions. The moderator also facilitates interaction and covers key topics and questions in a prepared outline. Because a secondary goal of the current study was to examine the attitudes and opinions of various constituents within the service delivery network, group membership was considered a criterion for creating contrasting subgroups. Inclusion of contrast variables in a sample design is useful for comparing attitudes between subgroups and for determining which attitudes are common. ${ }^{20}$ In the present study, focus group interviews were conducted separately with family caregivers and service providers. Both groups provide care and services for people with dementia as part of the formal and informal service delivery network. Thus, being a care provider is considered the control characteristic.

Based on these contrast and control characteristics, focus group interviews were conducted with 11 groups of family caregivers and eight groups of service providers in the four rural areas selected as intervention sites for the COEP-Michigan's "Thumb" Area, the Upper Peninsula, Northeast Michigan, and Mid-Michigan. As depicted in Figure 1, the catchment area for the Thumb Area 
Figure 1. Map of Michigan, depicting COEP intervention sites.

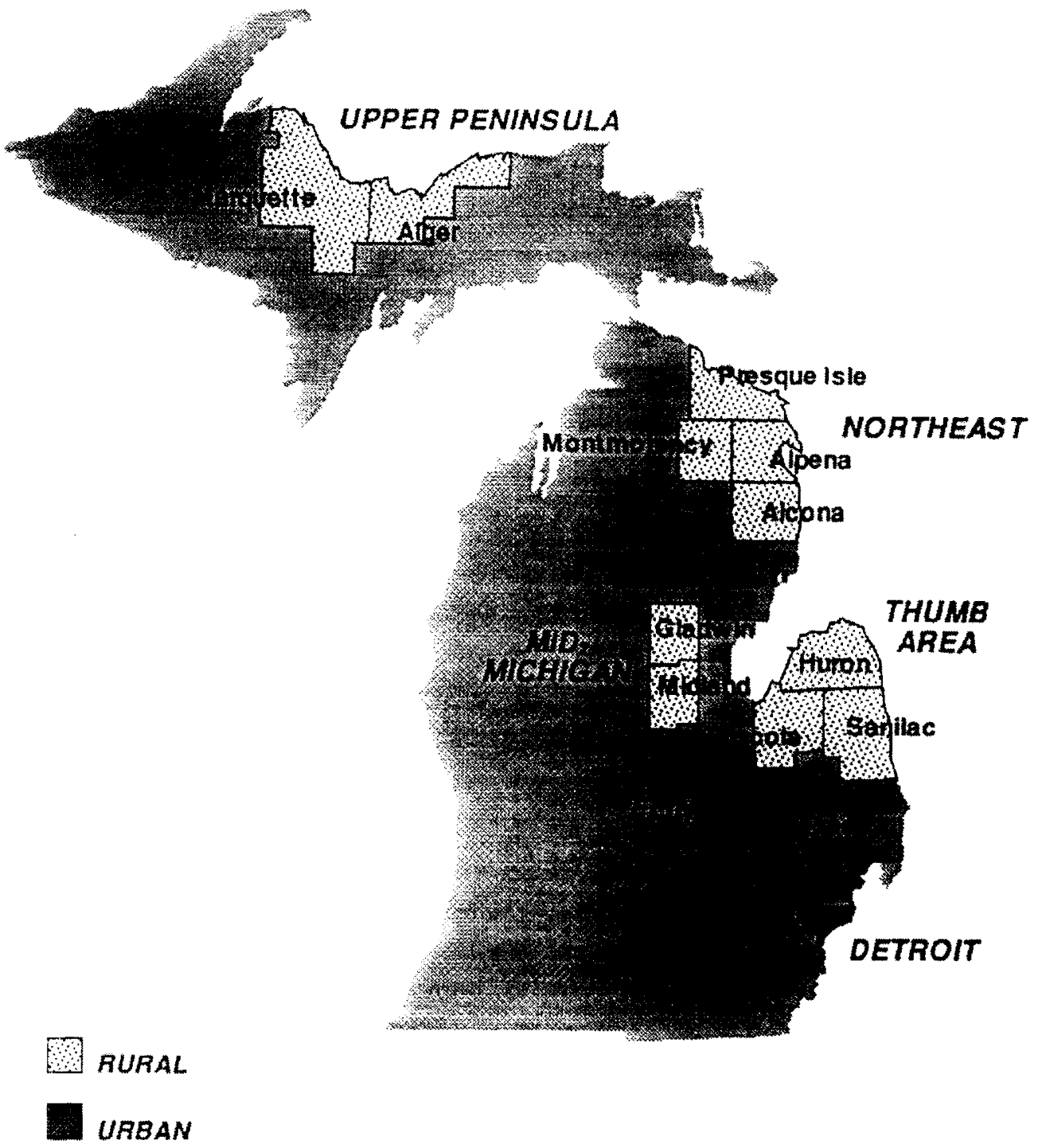

site includes Sanilac, Tuscola, and Huron counties; the Upper Peninsula site includes Marquette and Alger counties; the Northeast site includes Alcona, Alpena, Montmorency, and Presque Isle counties; the Mid-Michigan site includes Gladwin and Midland counties. (Educational interventions were planned and implemented in six sites in Michigan. The present study focuses only on the four rural sites.)

Participants were selected by local advisory boards established at each site and included health care professionals, staff of govemment, social service and voluntary agencies, community leaders, and family caregivers who were recruited by a site coordinator in each community. ${ }^{16}$ Local advisory board members also assisted in identifying interested family caregivers, primarily by soliciting the involvement of local Alzheimer's disease support groups. The number of participants in each group ranged from nine to 15 .

\section{Procedures}

Two health educators with Master's level training in public health and expertise in qualitative data collection served as facilitators for the interviews. As part of the introduction, the facilitators stated that the goal of the discussion was to explore attitudes about dementia and services for people with dementia. Participants were informed that results would be used in the development of community-based dementia education interventions and that their responses would be kept confidential. The procedures involved in audiotaping were explained and a 
tape recorder was set up in a visible location. Verbal consent to record was obtained in advance. Each focus group interview took approximately two hours and was held at a location suggested by the local advisory board. In order to develop descriptive profiles, participants were asked to complete a brief demographic questionnaire after the focus group interviews.

The following questions were included in the focus group interview protocol:

- How aware and knowledgeable is your community about dementia?

- How aware do you think people are about services for people with dementia in your community?

- What barriers have you or others faced in obtaining services in your community?

- How would you characterize the coordination and communication among various components of the service delivery system? and

- What are your community's strengths?

Several additional questions about the availability of services and recommended strategies to improve the service delivery network were also included:

- What types of information about dementia are available in your community?

- What can be done to improve the information and referral system for people with dementia and their families? and

- What kinds of education and training programs would best address the concerns you have?

The audiotapes were transcribed after each interview, yielding approximately 50 pages of transcript. Ethnograph, ${ }^{21}$ a software program designed to facilitate examination of qualitative data was used to analyze the transcripts. First, a list of key ideas, phrases, and verbatim quotations was generated. Next, major themes and subthemes were extracted and quotations to illustrate each subtopic were selected. ${ }^{22}$

\section{Results}

\section{Descriptive profiles}

A total of 138 service providers and family caregivers participated in the study. Of the 87 family caregivers, 77 percent were women, 99 percent were white, 78 percent were married, and 91 percent completed at least high school. The mean age of participants in this group was 64 , with a range of 22 to 85 . Of the 63 service providers, 83 percent were women, 97 percent were white, 73 percent were married, and all completed at least some college. The mean age of participants in this group was 48 years, with a range of 23 to 79 years. The majority of family caregivers (90 percent) and service providers ( 68 percent) reported having personal involvement with a relative or friend with dementia.

\section{Themes and sub-themes}

The general themes that emerged from the focus group transcripts included: myths and misconceptions about dementia; awareness of dementia; structural, attitudinal and illness-specific barriers to effective service delivery; and community strengths. Quotations that illustrate each of these themes and corresponding sub-themes are summarized in the next section.

\section{Myths and misconceptions about dementia}

\section{Dementia is a mental illness}

"...you still have the tag on Alzheimer's disease that people have mental illness and are embarrassed to bring it out in public. Grandpa's going nuts. Terrible."

"It's amazing how many referrals have come through our community mental health. I think that's because the family has this idea that ... something is wrong mentally."

\section{Symptoms of dementia are part of the normal aging process}

"I encounter some folks that think it must be Alzheimer's, that it's a natural thing with old age and what can we do about it anyway? So, we'll just handle it as long as we can, rather than being more assertive and aggressive about seeking out information, seeking the definite diagnosis, looking into services and all that."

"...there are still doctors who see it as senile dementia and as just a natural part of aging ...can't do anything about it anyway, so why refer them on to use up our tax dollars for more tests?"

"My mom's doctor said if you really want to get the complete story, have her go to a Neurologist... And she said, 'No way am I going to a doctor, I'm 82 years old ... I expect this." 


\section{Nothing can be done for people with dementia}

"The physicians ... don't have a pill to give you, they don't have the operation to cure you, they can't do anything for Alzheimer's."

"I think at least half of the professionals think it's hopeless, if not more than half."

Memory loss is a sign that dementia is inevitable

"Every symptom [of memory loss] begins to become Alzheimer's or possible Alzheimer's. I think it's getting blamed for a lot of things that aren't there."

"When they ... recognize it [memory loss] you need to stop the panic. They [older adults] jump to conclusions that it's Alzheimer's when maybe it's something else."

\section{Misconceptions about the cause/nature of dementia}

"I think that if you're connected with the disease, the first thing people think of, and possibly sometimes the only thing, is memory loss...you say Alzheimer's, and they say memory loss."

"What is the difference between senility and Alzheimer's? Is there a fine line or is it the same? I think we're just calling senility Alzheimer's disease."

"The way he [the doctor] described it, is that your brain is made up of a lot of little bubbles and as you grow older they burst and you forget how to do things."

\section{Awareness of dementia}

\section{Media attention}

"You hear the news talking about Alzheimer's."

"I don't think there's a single series on TV that has not had someone depicted with Alzheimer's disease...that has helped to make people more aware of it."

"I got a hold of an article about Alzheimer's disease and she acted just like it said in the article. I believe it was in Newsweek, back in about 1980. Prior to that, I never heard of Alzheimer's disease."

\section{Awareness among the public and service delivery network}

"If you're out in the community ... you don't really see that many people with Alzheimer's because most of them are kept home. A few of them get out and they go places, but it's rare that you see it."

"It's really hard...to find a family that Alzheimer's hasn't...touched in some way."

"We're just now getting some community leaders to acknowledge problems with alcohol and drugs in our county. We have a long way to go before they admit that some of our families have dementia and maybe it's in the genes."

Awareness of services, interventions and treatment for people with dementia

"People don't know that there are methods to deal with the difficult behaviors...and there are some simple things, behavior modification...that can help."

"There are medicines they're working on. Tacrine has just been approved by the [Federal] Drug Administration. That's something that people should be aware of."

"No one knows what respite care even means."

"One of the things I' $m$ asked to do as a professional is to make recommendations to family members or to the patients themselves about the kinds of things this person should be doing or not doing. Should they be driving, taking their own medications without supervision, paying their bills? The families are often looking to me to make suggestions-where do I get help for these issues?"

\section{Barriers to effective service delivery}

\section{Structural barriers}

\section{Lack of coordination in the service delivery network}

"We don't necessarily act regionally...it's county by county and defined by social services and mental health and public health...they don't overlap much...we're not really aware of what's in the other counties."

"Our county has a lot of resources, but they are rather disconnected and disorienting, particularly to family members."

"There's a particular group of agencies who do cooperate with each other, but we can't draw in the other agencies. It's real difficult...either no time, no funds, or there's no staff to do it. The interest is just not there..." 


\section{Cost of services}

"...it comes down to an ordeal with family members who can't afford to provide care for their loved ones and consequently end up being a nursing home placement ... there needs to be some kind of a match situation or a sliding scale. Up in the rural area here, people are on limited budgets."

"They (caregivers) don't feel that they can afford to pay somebody $\$ 7$ an hour to stay with their loved one for them to go to support groups to get help to deal with the rest of the hours."

"Well, cost is definitely a factor for a lot of people. They don't have insurance, or can't afford insurance, they're not going to go see a specialist and have multiple testing done."

"Some families who have the means will go a step further and take their families...down state to try to get a further diagnosis. But, there's a lot of people who can't afford that, or they're too stressed out to go any farther with it and they just try to make do with what they've got."

Service agencies are overburdened, understaffed, or unavailable

"Agencies are understaffed. They need more help. They get behind sometimes because they can't take care of all the patients that they have."

"Mental health is becoming overburdened ... there are many (people with dementia) on waiting lists ..."

"There is a lack of money available for respite...there's not enough resources to handle all of this."

\section{Distance and transportation}

"I used to get somebody who would come and stay an hour ... you take a half hour to drive somewhere and then you have to turn around and do a half hour back ... the hour was gone, you didn't have time to do anything in town."

"...a barrier is that counties (in our area) are large ...part of the resistance to taking them to day care is because it's $20,40,50$ miles to get there. So you're not just thinking of the time of the day care, it's the time of getting the client ready and the transporting."

\section{Reimbursement policies for services are too restrictive}

"We know doctors who would put a family member in a nursing home before they'll recommend home care...because they don't get reimbursed from home care..."

"It's the same trouble with home health. We know that home health would be a good option, but we can't find a skilled nurse and we can't figure how to get services in the home that are Medicare reimbursable."

"The person who has more income doesn't qualify for Medicaid, but doesn't have enough resources to hire caregivers, and yet it would cost the system less money if they could be cared for at home than if they were in the nursing home."

\section{Lack of access to comprehensive diagnostic and assessment services}

"...the doctor doesn't even ask about Alzheimer's, they just basically check your lungs, check your heart and out the door you go. That's the end of it. You get nothing but that around here."

"A lot of folks... have had a diagnosis but have never had any ruling out tests, and I'm thinking...how many of these people have brain tumors or the wrong medications, or are severely depressed?"

\section{Family physicians do not always make referrals for services}

"...he diagnosed her. He did not tell us one thing about who to contact. The only thing he told us is I suggest you get a guardian."

"Some of the family care physicians feel that once they make a referral to a specialty...that they are going to lose that patient...there's that perception out there and therefore a lack of referral for the evaluation."

"We have an aging physician population...they are really reluctant to relinquish control over their patients. It's difficult to get referrals out of them."

"Well, physicians don't like to make referrals to outside agencies, so I tell clients that there are services out there and I give them brochures and they can be self referrals. That way, I'm not going against the physicians' wishes and I don't have to document that. There are ways of getting around it."

\section{Attitudinal barriers}

\section{Stigma of dementia}

"...the guilt and shame associated with cancer is 
gone, so many families have dealt with it. We need to see that happen with Alzheimer's disease ..."

\section{Stigma and guilt about seeking help and receiving} services

"In this community, going to see a psychiatrist (for diagnosis and assessment) is the end of the world. Sometimes I (a local psychiatrist) want to wear a hood over my head when I go out in public. Things have to be bad for them to come to me with their troubles."

"With Alzheimer's, it takes a long time for them [family members] to come to us to access services...it's very difficult for them because of the guilt associated with it."

\section{Value of self-reliance}

"I think there's a self-reliance and an independence in a rural farming community."

"If you're a good citizen, you won't ask for help. You'll take care of it..."

"There's also, a stronger feeling [in isolated rural areas] that...we don't take help from anyone."

\section{Belief that family members should be responsible for} care

"...they feel it's their parent or their relative, it's their responsibility...there's an obligation there and they go with it as long as they can. The person they're caring for...wants to remain in the home or in the context of the family. So that's why they wouldn't go out for help at all."

"...a lot of families that were brought up here with the old heritage of you take care of your own and that's it...you keep your problems in the family."

\section{Reluctance to seek services until a crisis occurs}

"I don't think a lot of people would look or search for help unless it really got critical and they simply couldn't handle it."

"By the time we get there, the caregiver is worse off than the client because they're run down and they're ill."

\section{Denial of symptoms}

"In most cases, there's that time of denial...family members know that the person has a problem, but the actual person afflicted is going through a denial stage."
"By the time the family recognizes memory loss or by the time anyone is willing to confront it, it's pretty severe."

"I think one of the big problems with the disease is that people can't accept it or cope with it. Even members of the family."

"You're in denial for such a long time because you're trying to protect your loved one. You don't want anyone to know that he isn't what he should be. After a few years, you're not able to carry on the charade and you finally have them diagnosed."

"My eldest son denied for a long time there was anything wrong with his father. I think they ... don't want to admit to themselves that this is happening to someone they care about."

"She can't remember names or things that she did or things that people told her, but she doesn't think there's anything wrong with her. We're worried about her living by herself "

\section{Reluctance to seek health care in general or care from specialists}

"...we have a lot of elderly in this community who still do not go to any physician or the health department. We [Commission on Aging] have become the stop gap where they call us... it's really amazing that they have never gone to any type of health care."

"I think that is a problem...especially with the elderly patients...they say, 'Dr. Jones has been my doctor ever since I can remember and he's going to take care of all my problems and I'm not going to see a specialist or go to another clinic as long as he's here and willing to take care of me."

\section{Ageism}

"There are a lot of doctors that don't like to treat older people. Probably [because they] don't know what to do. They can't help us if they don't know what to do."

"I can't say that it's lack of knowledge on their part. It's lack of interest and the part I find up here, whether they have Alzheimer's or dementia, it's basically, 'They're getting old and we don't care... put them in a home... let them die.' And I've heard them say it."

"I don't want to spend money on this demented old person. You're spending my inheritance." 
"I'm really saddened to see that the older the person is, the less even the family is willing to take steps to make life better for that person."

\section{IIIness-specific barriers}

\section{Patient cannot participate in decision making}

"You're dealing with someone who's not rational so you can't counsel them, you can't speak to them logically about what they're doing and have them respond."

\section{Health care insurance is inadequate for people with dementia}

"Most of the insurance will not pay for care for Alzheimer's people, it's self-pay."

"... it's my understanding that nursing home insurance will not take people with dementia or, once they find out the person has dementia, the policy is void."

"For home care, they will not pay for someone to come in and care for an Alzheimer's client. You have to have an acute medical problem that's diagnosed and that they can verify."

\section{Fear of the diagnosis of a dementing illness}

"I think that people are afraid to find out that their family members may be diagnosed as having that problem because they're going to lose that person, even though the body may still be there."

"I see a lot of it when I go in the homes and talk to the husband, the wife, and the children-they want somebody else to handle it. They don't want to admit that their mother or father has that disease...they don't want the diagnosis."

\section{Concern about the role of family history in risk of being diagnosed with dementia}

"You think of it [dementia] when you get older ... whether it existed in the past in your family. . you hear that your mother or father died of this or had that, and you expect the same for yourself."

"The business of whether or not it's hereditary is a big concern to every family member."

\section{Community strengths}

\section{Community action and cooperation}

"Well, I think it's just the cooperation, being small, you know. Just word of mouth will travel a long way."

"...in this area...different groups can communicate...we know each other and we're a lot closer, we are able to coordinate and discuss things, whereas in a bigger area, they can't."

\section{Close-knit ties and long-established roots}

"We're not a large community, but small and closeknit. There are a lot of...large, extended families here."

"There are so many of our population who are quite a bit older...they're the roots of the community. They've been born and raised here...they're intertwined, people are related heavily here."

\section{Dedication and caring for residents in rural areas}

"Part of a rural community, especially if you've been there for three or four generations, is that you know a lot of people and...the people, as a rule, care...you know your next door neighbor and other people in the community."

"There's a high commitment on the part of families, or extended family, or neighbors...to help these people (with dementia). It's not like a large metropolitan area where you...lock your door and you have no idea who lives next to you."

\section{Strong cultural identity}

"...most of our problems are... because we are rural, but that's one of our strengths too as far as dealing with people...networking and having more community atmosphere."

"I think by virtue of the fact that we're so isolated it makes us stronger, culturally."

\section{Discussion}

\section{Myths, misconceptions, and general awareness of dementia}

The present study confirms previous research by identifying commonly held myths and misconceptions which influence how family members and communities respond to people with dementia. For example, focus group participants indicated that symptoms of dementia are viewed as part of the normal aging process for which nothing can be done. Dementia shares a stigma with mental illness and people with dementing illnesses are seen as "crazy" or "wrong mentally." There is great confusion about the cause and nature of dementia, with people referring to it as old timers and senility, or assuming that all memory loss is a sign of dementia. 
Because these beliefs may prevent or delay utilization of needed services, including a comprehensive diagnosis and assessment, efforts to increase public awareness of dementia are extremely important. Although attention to the topic has certainly increased in recent years, some of the information disseminated by the media has resulted in more confusion than understanding, especially selected findings from ongoing research efforts that are often taken out of context. For example, research on the role of genetic factors and family history in Alzheimer's disease is commonly misunderstood to mean that a diagnosis of Alzheimer's disease is inevitable if the disease "runs in your family." ${ }^{23}$ Similarly, the public has been exposed to promises about the effectiveness of new medications to treat symptoms of dementia and the availability of a blood test that can be used for diagnostic purposes. ${ }^{23.24}$ Because the public generally has difficulty interpreting research evidence, ${ }^{25}$ misunderstandings may accelerate unnecessary fears about the risk of being diagnosed with dementia or provide false assurance about the accuracy of unproven diagnostic tests or the potential of currently available treatments. Thus, although media attention to, and awareness of dementia has increased, both knowledge and practical understanding of the disease among the general public are limited, except for families who have experienced dementia firsthand.

\section{Barriers to coordinated and effective service delivery}

\section{Structural barriers}

Several barriers to effective service delivery were identified in this study, including a lack of coordination of health and social services agencies, the prohibitive cost of services, the lack of available services (especially diagnostic and assessment services and respite care) and appropriate referrals, restrictive reimbursement policies, as well as understaffing and high demand for existing services. Although these barriers have been identified previously, particularly in rural areas, ${ }^{26}$ the comments made by family caregivers and service providers during the focus group interviews reflect how these structural barriers affect help-seeking behavior and the experience of being a caregiver. Family members report several frustrations related to the utilization of needed services: being put on a waiting list for services that they need immediately; physicians who do not provide an adequate diagnosis or referral to services; difficulties understanding complex Medicare reimbursement policies; and the inadequacy of health insurance that does not cover essential services.

Caregivers and service providers reported that physicians are sometimes reluctant to make referrals to specialists for diagnosis and assessment because they fear losing their patients. Alternatively, some families are reluctant to seek a diagnosis from a specialist because they feel they would be going against their doctor's wishes. Ultimately, both of these attitudes reduce the number of people who receive an adequate diagnosis and assessment for symptoms of dementia. Access to transportation is another major problem in rural areas, especially for older adults who may be unable to drive for reasons of health or poverty. Even when transportation is available, however, the need to travel long distances can effectively eliminate the intended benefit of support services (e.g., respite/adult day care, support groups) because the free time caregiver's gain is spent in the car.

\section{Attitudinal barriers}

Several strongly held beliefs reduce the likelihood that people in need of care for dementia will receive help, especially in rural areas. As mentioned previously, many focus group participants indicated that denial of symptoms due to the stigma of the disease is common. Family members are also reluctant to seek community-based services because they are seen as 'hand outs' or 'welfare.' These misconceptions, in combination with the belief that family members should be self-reliant and solely responsible for the care of older adults, create a very unfavorable situation for pursuing appropriate health care options. Even when people do seek help, the response they receive from health care professionals is not consistently appropriate. Ageism and misconceptions about dementia among health care professionals reduce the likelihood that people will receive adequate information and referral to needed services.

\section{IIIness-specific barriers}

Several barriers to effective service delivery are specific to the nature of dementia. Except in the early stages of the disease, people with dementia are usually not able to participate in decision making about their care. This complicates efforts to provide needed services, because the patient cannot always understand the need to seek services and may be uncooperative. Additionally, because dementia is not considered an acute or a terminal illness, family members are frequently denied insurance coverage for needed services. People fear a diagnosis of a 
dementing illness because of the pain associated with losing a family member to a disorder that takes such a devastating toll on the patient and family, the discomfort experienced in confronting persons who are exhibiting symptoms from their cognitive losses, and the realization that family members might be at higher risk of being diagnosed due to the hereditary nature of the disease.

\section{Building on community strengths and resources}

In addition to identifying barriers to coordinated and effective service delivery, the focus group interviews also allowed participants to articulate strengths and resources in their community. Participants mentioned the small size of their community as being advantageous to cooperation and coordination of services, and that strong ties in the communities, genuine dedication and caring for residents, ${ }^{7}$ and a strong cultural identity were all valuable in their work as professional or family caregivers. These strengths provide a solid foundation for implementing the COEP in rural communities.

\section{Implications for intervention}

A second goal of the focus group interviews was to establish priorities for community-based education and training programs in dementia and elicit suggestions to increase awareness of dementia among the public. Participants indicated that health care providers, service providers, hospital staff, home care agencies and long term care facilities should be primary target audiences for the intervention. In particular, physicians have an important role to play in diagnosing and assessing the patient, informing the family about the disease, and providing referrals to needed services. Caregivers and service providers who participated in the focus group interviews, however, suggested that most local physicians were inadequately prepared to respond to people with dementia due to lack of training and expertise about dementing illnesses. According to participants, some physicians reinforced the misconceptions that are commonly expressed among the general public, particularly that symptoms of dementia are a normal part of the aging process and that nothing can be done for the disorder. Additionally, local physicians (and their office staff) lacked awareness of information and referral sources, and were uninformed about the benefits of diagnosis and intervention early in the disease process. Participants also suggested that physicians need to be informed that a referral to a local geriatric assessment team or diagnostic and assessment center will not jeopardize their relationship with their patient. After the diagnosis is made, the primary care physician can provide long term management of the disease and serve as the gatekeeper for specialized care and treatment.

Focus group participants also indicated a need to target educational interventions to information and referral agencies (e.g., staff of Area Agencies on Aging), government agencies (e.g., local health department, Commission on Aging), law enforcement agencies, and the general public. For example, outreach to service clubs (e.g., Lions, Kiwanis, Rotary), churches, the local business community, and community centers was recommended. Another suggestion was to develop a speaker's bureau as a mechanism to disseminate information to the community. A supportive community and informed public is especially important given the nature of the symptoms of dementia (e.g., wandering, getting lost in familiar places). Because focus group participants expressed concern that people don't understand the disorder unless it affects them personally, efforts to educate the public were thought to decrease the stigma, dispel myths and misconceptions as well as to increase community awareness of the disorder. Mass media, including newspapers, radio, local access public television, billboards, newsletters, educational videos, senior fairs, public libraries, and the local telephone book were suggested as effective means of increasing awareness of local services. Families are often the primary caregivers for as long as possible and do not seek services until a crisis has occurred, often late in the disease process when the stress of being a full time caregiver has taken a toll. Consequently, caregivers may also benefit from education and training that focuses on skills to manage difficult behaviors, maintain optimal self-care, cope effectively, initiate therapeutic activities with the family member with dementia and understand complex health care insurance policies.

Several limitations of the present study should be noted. First, as with all focus groups, the sample used was small and participants were not selected randomly. ${ }^{18}$ Focus group interviews, however, are adept at capturing in-depth contextual detail and assisting in the process of exploring the social context and subjective meaning of dementia in the community. ${ }^{27}$ Also, data for the four sites is combined. As noted by Krout, ${ }^{10}$ there is likely considerable diversity among rural communities in attitudes and values, availability of services, and barriers to service utilization.

In summary, focus group interviews with family caregivers and service providers proved to be effective in 
identifying attitudinal and structural barriers, educational needs, and strengths and resources in the service delivery network for people with dementia and their family members. As part of the community development approach to educational outreach, results were shared with the local advisory boards established at each of the intervention sites during a community forum and planning session. This open dialogue provides the needed framework from which to develop educational interventions that are tailored to address local concerns and reflect the priorities identified in the needs assessment. Most importantly, the process of conducting the focus group interviews fostered a level of community involvement, ownership, group identity, and commitment to the COEP that will be vital to the long term change in the response to people with dementia and their families in rural communities.

\section{Acknowledgments}

The authors thank the members of the local advisory boards for their contribution to the focus group interviews, Sara B. Holmes for serving as a consultant to the project, and Pegeen A. McGhan for her assistance with manuscript preparation. This research was supported by grants from the US Public Health Service (NIH, NIA \#P50-AG08671 to the Michigan Alzheimer's Disease Research Center and \#R25-AG11219 to the Michigan Public Health Institute) and from the Health Services Resources Administration (CSH 000148-01-0) to the Michigan Department of Mental Health. Collaborators in the COEP include the Michigan Department of Public Health, the local chapters, Executive Directors, and the Michigan Council of the Alzheimer's Association, and the Michigan Department of Mental Health.

\section{References}

1. Shope JT, Holmes SB, Sharpe PA, Goodman C, Izenson S, Gilman S. Foster NL: Services for persons with dementia and their families: A survey of information and referral agencies in Michigan. Gerontologist. 1993;33:529-533.

2. US Congress, Office of Technology Assessment: Confused minds, burdened families: Finding help for people with Alzheimer's disease and other dementias. OTA-BA-403, Washington, DC, US Government Printing Office, 1990.

3. US Department of Health and Human Services, Public Health Service, National Institutes of Health, National Institute on Aging: Strategy Plan for Alzheimer's Disease Education and Referral (ADEAR) Center. Bethesda, MD, 1988.

4. Collins C. Stommel M, Thiele J: Knowledge and use of community services among family caregivers of Alzheimer's patients. Rockville, MD, US Department of Health and Human Services, 1989.

5. Collins C, Stommel M. King S, Given CW: Assessment of the attitudes of family caregivers toward community services. Gerontologist. $1991: 31: 756-761$.
6. Advisory Panel on Alzheimer's Disease: Fourth Report of the Adivisory Panel on Alzheimer's Disease. NIH Publication No. 933520. Washington, DC, Superintendent of Documents. US Government Printing Office, 1993.

7. Shope IT. Holmes SB, Sharpe PA, Goodman C, Izenson S, Gilman $S$ : Planning for a statewide network of dementia assessment services: A survey of geriatric assessment services in Michigan. American Journal of Alzheimer's Care and Related Disorders and Research. 1992;7:31-36.

8. Schauer PM, Weaver P: Rural elderly transportation. In: Krout JA (ed.), Providing community-based services to the rural elderly. Thousand Oaks. CA Sage Publications. Inc. 1994;23-41.

9. Windley PG: Community services in small rural towns: Patterns of use by older residents. Gerontologist. 1983; 23, 180-184.

10. Krout JA: An overview of older rural populations and communitybased services. In: JA Krout (ed.): Providing community-based services to the rural elderly. Thousand Oaks, CA, Sage Publications, Inc., 1994:23-41.

11. Melton GB, Childs AW: Rural psychology. New York, NY, Plenum, 1983.

12. Roybal ER: Mental health and aging: The need for an expanded federal response. Am Psychol. 1988;43:189-194.

13. Altman DG, Endres J, Linzer J, Lorig K, Howard-Pitney B, Rogers $\mathrm{T}$ : Obstacles to and future goals of ten comprehensive community health promotion projects. J Community Health. 1991;16:299-314.

14. Bracht N (ed.): Community organization strategies for health promotion. Newbury Park, CA, Sage Publications, Inc., 1990.

15. Minkler M: Improving health through community organization. In: Glanz K, Lewis F, Rimer B (eds.), Health behavior and education: Theory, research, and practice. San Francisco, CA, Jossey-Bass, 1990. 16. Connell CM, Kole SL, Benedict CJ, Holmes SB, Gilman S, Beane GE: Increasing coordination of the dementia service delivery network: Planning for the Community Outreach Education Program. Gerontologist. 1994; 34: 700-706.

17. Basch $\mathrm{CE}$ : Focus group interview: An underutilized research technique for improving theory and practice in health education. Health Ed Quarterly. 1987; 14:411-448.

18. Basch CE, DeCicco IM, Malfetti JL: A focus group study on decision processes of young drivers: Reasons that may support a decision to drink and drive. Health Ed Quarterly: 1989;16:389-396.

19. Morgan DL, Kreuger RA: When to use focus groups and why. In: Morgan DL (ed.), Successful focus groups: Advancing the state of the art. Newbury Park, CA, Sage Publications, Inc., 1993.

20. Knodel J: Design and analysis of focus group studies. In: Morgan DL (ed.): Successful focus groups: Advancing the state of the art. Newbury Park, CA, Sage Publications, Inc., 1993.

21. Seidel JV, Kjolseth R, Seymour E: The Ethnograph: A user's guide (version 3.0) Amherst, MA, Qualis Research Associates, 1988.

22. Strauss A, Corbin J: Basics of qualitative research. Newbury Park, CA, Sage Publications, Inc., 1990.

23. Gruetzner H: Alzheimer's: A caregiver's guide and sourcebook. New York, NY, John Wiley and Sons, 1992.

24. Alzheimer's Association: Alzheimer's Association Newsletter. Winter 1992; 12,4.

25. Becker MH: The tyranny of health promotion. Public Health Rev. 1986;14:15-25.

26. Redford LJ, Severns AB: Home health services in rural America. In: Krout JA (ed.), Providing community-based services to the rural elderly. Thousand Oaks, CA. Sage Publications, Inc., 1994:221-242. 27. Wolff B, Knodel J, Sittitrai W: Focus groups and surveys as complementary research methods: A case example. In: Morgan DL (ed.), Successful focus groups: Advancing the state of the art. Newbury Park, CA, Sage Publications, Inc., 1993. 